\title{
Major factors for facilitating change in behavioral strategies to reduce obesity
}

\author{
This article was published in the following Dove Press journal: \\ Psychology Research and Behavior Management \\ 2 October 2013 \\ Number of times this article has been viewed
}

\author{
Riccardo Dalle Grave' \\ Elena Centis ${ }^{2}$ \\ Rebecca Marzocchi ${ }^{2}$ \\ Marwan El Ghoch' \\ Giulio Marchesini² \\ 'Department of Eating and Weight \\ Disorders, Villa Garda Hospital, Garda \\ VR, ${ }^{2}$ Unit of Metabolic Diseases \\ and Clinical Dietetics, Alma Mater \\ Studiorum University, Bologna, Italy
}

Correspondence: Giulio Marchesini Unit of Metabolic Diseases and Clinical Dietetics, Alma Mater Studiorum University, Policlinico S Orsola,

Via Massarenti 9, I-40I 38 Bologna, Italy

Tel +3905 16364889

Fax +3905 I6364502

Email giulio.marchesini@unibo.it

\begin{abstract}
It is very unlikely that our obesity-promoting environment will change in the near future. It is therefore mandatory to improve our knowledge of the main factors associated with successful adoption of obesity-reducing behaviors. This may help design more powerful procedures and strategies to facilitate the adoption of healthy lifestyles in a "toxic" environment favoring the development of a positive energy balance. The aim of this review is to describe the main factors associated with successful adoption of obesity-reducing behaviors and to describe the most recent development, limits, and outcomes of lifestyle modification programs. The evidence regarding predictors of weight loss and weight loss maintenance remains largely incomplete. It is necessary to develop strategies matching treatments to patients' needs to improve successful weight loss and its maintenance. How to detect and how to address these needs is a continuous, challenging, research problem.
\end{abstract}

Keywords: weight loss, physical activity, food intake, motivational interviewing, behavioral therapy

\section{Introduction}

Despite great interest and numerous interventions in the US, Europe, and other industrialized nations, overweight and obesity are increasing with an epidemic evolution. Countries with emerging economies, such as India, the People's Republic of China, South Africa, Argentina, Guatemala, and the Pacific Islands, are also increasingly affected by obesity. ${ }^{1}$ The National Institutes of Health and World Health Organization (WHO) have reported an average increase in the prevalence of overweight and obesity of approximately $0.3 \%-0.8 \%$ per year over the past three decades. ${ }^{2,3}$ The total number of overweight adults exceeds 1.6 billion, with over 400 million obese individuals; according to $\mathrm{WHO}$, more than 2.3 billion adults will be overweight and more than 700 million will be obese worldwide by $2015 .^{4}$

In children and adolescents, the prevalence of overweight and obesity is also an emerging crisis. In 2010, WHO estimated the number of overweight children under the age of 5 years to be over 42 million, with nearly 35 million overweight children living in developing countries. ${ }^{5}$ Overweight children typically progress to become obese adolescents and adults. ${ }^{6}$

The increasing burden of obesity is alarming because of its broad spectrum of acute and long-term complications, imposing substantial human and economic costs on individuals, families, health care systems, and society. ${ }^{7}$ Overweight and obesity are associated with a very high prevalence of comorbidities, including diabetes and all features of the metabolic syndrome, cancer (liver, kidney, breast, endometrial, prostate, 
and colon) and cardiovascular disease. Moreover, high-grade obesity results in higher mortality rates. ${ }^{8}$ Depending on age and race, obesity has proven to be associated with a 6-20-year decrease in life expectancy. ${ }^{9}$ One kilogram of weight gain increases the diabetes risk by $4.5 \%-9.0 \%$ and cardiovascular risk by $3.1 \% .{ }^{10}$ Understanding all the components of the chain that cause obesity may be important for identifying focused solutions.

Obesity is a multicomponent disease arising from a complex interaction between genetic and environmental factors. However, the dramatic increase in obesity prevalence observed in the last decade seems attributable mainly to environmental changes promoting the intake of energydense foods and/or reduced physical activity due to the high number of sedentary jobs, different transportation systems, and increasing urbanization. Changes in dietary and physical activity patterns are thus mainly the result of environmental and societal changes associated with a lack of supportive policies in areas such as health, agriculture, transport, urban planning, environment, food processing, distribution, marketing, and education. A "running society" with a high level of stress develops compensatory and gratifying behaviors, where eating has a primary role, strengthened by the food industry, food advertising, and the availability of energy dense foods.

People in the Western world have difficulty in identifying hunger and satiety cues. Hunger appears to be stimulated by the presence of favorite foods, meal times, and social cues to eat. ${ }^{11}$ Individuals eat more when more food is available, when there is a greater variety of food options, and visual evidence of consumed food is eliminated, ${ }^{12}$ indicating that hunger and satiety are at least in part mediated by external cues. Furthermore, the social environment has effects on food consumption. For example, compared with eating alone, individuals eat $35 \%$ more when eating with another person, 75\% more with three other persons, and 96\% more with a group of seven or more. Bright lights, hard surfaces, bright colors, and fast music all encourage people to eat more quickly, whereas slow music causes people to continue eating 11 minutes longer on average. ${ }^{12}$

Behavioral structure, mainly towards food, begins in the first years of life. Parents, as food providers, enforcers, and role models, certainly have a strong influence in shaping their children's dietary behavior, weight status, ${ }^{13}$ and lifestyle (physical activity).

The optimal strategy to address the obesity epidemic and to facilitate the weight loss efforts of obese individuals is to create a healthy environment favoring the adoption of healthy behaviors through an incisive public health intervention. However, even if some promising results have been achieved in the last few years, it is very improbable that the obesitypromoting environment will change in the near future. For this reason, it is essential to develop more powerful procedures and strategies to help individuals adopt a healthy lifestyle in a "toxic" environment favoring the development of a positive energy balance.

\section{Main factors associated with successful adoption of obesity-reducing behaviors}

Lifestyle changes and weight management remain dynamic processes where relapse is possible at any stage of treatment. Therefore, there is a strong interest in understanding the process that promotes behavior and successful adoption of healthy habits. ${ }^{14}$

The mere knowledge of healthy nutrition standards and dietary prescriptions along with regular physical activity programs are not sufficient to reach and maintain a healthy lifestyle and reduce excess bodyweight. Personal motivation for change plays a fundamental role in modifying unhealthy habits and lifestyle. Miller and Rollnick ${ }^{15}$ identified two factors considered to be important components to behavior change, namely discrepancy and self-efficacy.

The concept of discrepancy, based upon Festinger's cognitive dissonance, ${ }^{16}$ focuses on the contradiction between how a person currently sees him/herself and how he/she would like to be in order to correspond to his/her ideal self-image, value system, and expectations. Similarly, other cognitivebehavioral theories refer to the concept of self-regulation where motivation to change is based upon a comparison between the goal to be pursued and perception of the current situation; ${ }^{17}$ behavior, situations, and conditions not fitting with self-image are perceived as threats and can trigger a behavior change. ${ }^{18}$

The second factor, self-efficacy, is a key construct popular within the different theories of health psychology (social cognitive theory, ${ }^{19}$ protection motivation theory, ${ }^{20}$ transtheoretical model, ${ }^{21}$ health action process approach, ${ }^{22}$ and as perceived behavioral control, the theory of planned behavior). ${ }^{23}$ It has been defined as "the belief in one's capabilities to organize and execute the courses of action required to produce given attainments." ${ }^{24}$ According to these theories, both discrepancy and self-efficacy have to be present to activate change. Specifically, self-efficacy might be an important predictor of a number of different health behaviors, including reduced alcohol consumption, ${ }^{25}$ smoking cessation, ${ }^{26}$ and 
condom use. ${ }^{27}$ In the physical activity area, self-efficacy has qualified as an important predictor in adults ${ }^{28,29}$ for both adoption and maintenance of physical activity. ${ }^{30-32}$

Several studies and reviews have aimed at identifying predictors and correlates of weight loss and maintenance; the complexity of obesity leads to contradictory results and any prediction is difficult. While considerable evidence on successful weight loss exists, much less is known about the psychologic processes associated with long-lasting weight management. ${ }^{33} \mathrm{~A}$ study provides empiric support to the notion that influencing an individual's perception of self-efficacy and intrinsic motivation for regular exercise from the early beginning of the program is related to overall success. ${ }^{34}$ Strategies to increase self-efficacy are well described and include use of vicarious/enactive experiences (eg, learning from or observing others who have been regularly active), inducing emotional activation (eg, experiencing the psychologic benefits from regular exercise), and also verbal/social persuasion. ${ }^{35}$ Increased intrinsic motivation for physical activity remains the strongest predictor of long-term results. ${ }^{35}$

As a central tenet of the self-determination theory, intrinsic motivation describes a person's overall satisfaction in participating in a given activity for the sake of the activity itself. ${ }^{36}$ Whereas extrinsic motivation is contingent on reaching a goal separated from behavior (eg, getting a reward, compliance with others' expectations, not feeling guilty), intrinsically motivated behaviors originate in the person (ie, they have an internal locus of causality), are internally regulated, and are inherently enjoyable and interesting. According to self-determination theory, engaging in activities that are intrinsically motivated (or well integrated with one's values) and not externally controlled is central to fulfill the human being's fundamental need for competence and autonomy. ${ }^{36}$

Social support also influences individual motivation and perseverance. The importance of social connections and the feelings of competence and autonomy noted when participants are successful with behavioral changes are consistent with the three tenets of the self-determination theory in enhancing intrinsic motivation. ${ }^{37}$ In this context, families represent another potential source of support for behavioral change. Family-based interventions can address the barriers to treatment; in turn, participants may facilitate behavioral change in family members, who are frequently at similar risk (see Table 1). ${ }^{38}$

A review has recently analyzed the evidence on psychologic factors associated with weight loss maintenance and relapse in obese adults. ${ }^{39}$ Eight psychologic factors affecting weight loss maintenance were identified: unrealistic weight loss expectations, failure to achieve weight loss goals,

Table I Analysis of psychologic factors associated with weight loss maintenance and relapse in obese adults ${ }^{39}$

\begin{tabular}{|c|c|c|c|}
\hline Factor & Studies (n) & Results & Implications \\
\hline $\begin{array}{l}\text { Unrealistic weight } \\
\text { loss expectation }\end{array}$ & 4 & Conflicting and inconclusive results & Further studies needed in this area \\
\hline $\begin{array}{l}\text { Failure to achieve } \\
\text { weight loss goals }\end{array}$ & 3 & $\begin{array}{l}\text { Conflicting results; even when goals are } \\
\text { not met, satisfaction seems to be important } \\
\text { in weight maintenance }\end{array}$ & Concept of satisfaction needs additional research \\
\hline $\begin{array}{l}\text { Dichotomous } \\
\text { thinking }\end{array}$ & 2 & $\begin{array}{l}\text { Dichotomous thinking is a very strong predictor } \\
\text { of weight regain at one-year follow-up }\end{array}$ & $\begin{array}{l}\text { Altering all-or-nothing thinking may be an effective } \\
\text { way to assist individuals in weight loss maintenance }\end{array}$ \\
\hline $\begin{array}{l}\text { Eating to regulate } \\
\text { mood }\end{array}$ & 3 & $\begin{array}{l}\text { Eating to regulate mood is a strong } \\
\text { predictor of weight regain }\end{array}$ & $\begin{array}{l}\text { We need to help individuals recognize the use of } \\
\text { food to regulate mood and to explore healthier ways } \\
\text { of dealing with emotional distress }\end{array}$ \\
\hline $\begin{array}{l}\text { Disinhibition versus } \\
\text { dietary restraint }\end{array}$ & 6 & $\begin{array}{l}\text { Low disinhibition, ability to maintain control } \\
\text { over eating and exercise, and dietary restraint } \\
\text { play a significant role in maintaining weight loss }\end{array}$ & $\begin{array}{l}\text { Specific programs increasing awareness of food } \\
\text { intake and favoring cognitive dietary restriction are } \\
\text { necessary for long-term weight loss maintenance }\end{array}$ \\
\hline $\begin{array}{l}\text { Perceived cost versus } \\
\text { benefit (decisional } \\
\text { balance) }\end{array}$ & 2 & $\begin{array}{l}\text { When subjects feel that the costs associated } \\
\text { with weight loss outweigh the benefits, } \\
\text { they stop the healthy behavior program }\end{array}$ & $\begin{array}{l}\text { Helping patients remember how important the } \\
\text { expected benefits are may restore a sense of reward } \\
\text { and prevent discouragement undermining the efforts }\end{array}$ \\
\hline Depression & 4 & $\begin{array}{l}\text { Results support the association between } \\
\text { higher levels of depression and failure } \\
\text { to maintain weight loss }\end{array}$ & $\begin{array}{l}\text { Monitoring patients' level of depression and intervening, } \\
\text { pharmacologically or otherwise, to prevent increased } \\
\text { depression leading to weight regain }\end{array}$ \\
\hline Body image & 3 & $\begin{array}{l}\text { More negative feelings about one's body } \\
\text { image are associated with weight regain; } \\
\text { improvements in and more positive feelings } \\
\text { about body image are associated with weight } \\
\text { loss maintenance }\end{array}$ & $\begin{array}{l}\text { It is important to help patients define themselves by } \\
\text { more than just body shape or size; referral for group } \\
\text { or individual therapy aimed at modifying thinking } \\
\text { patterns and specific actions could offer a greater } \\
\text { chance of success in weight maintenance }\end{array}$ \\
\hline
\end{tabular}


dichotomous thinking style, eating to regulate mood, disinhibition versus dietary restraint, perceived cost versus benefit, depression, and body image. The studies about the influence of the first two factors, ie, unrealistic weight loss expectation and failure to achieve weight loss goal, gave inconclusive and conflicting results, although supported by epidemiologic studies. ${ }^{40}$ The other factors were all associated with failure to maintain weight loss; emotional distress rather than hunger was the common trigger for eating, leading to weight regain which was also common whenever the costs associated with weight loss outweighed perceived benefits.

Of note, increased cognitive restraint of eating, decreased binge eating, external eating, disinhibition, and susceptibility to hunger were all associated with higher self control capacity in general, ${ }^{41}$ a concept close to the concept of self-efficacy. Specifically, a flexible pattern of restrained eating, characterized by a more gradual approach to eating, dieting, and weight control, is more successful than any rigid form of restraint, ${ }^{42}$ expressed by a dichotomous, all-or-nothing approach to eating and dieting. A flexible eating self-regulation pattern is also more likely associated with a healthier approach to physical activity, thus completely modifying lifestyle. ${ }^{43}$ Tools and approaches that could enhance the subjective experience of self-control could thus be taken into consideration to increase the long-term success of weight management.

In conclusion, psychobehavioral factors are more strongly associated with successful weight management than the satiety effect or other characteristics of diet. ${ }^{44}$ When tested in free-living conditions, diets with a different macronutrient content, particularly a different amount of protein and fibers, which by themselves could also have been expected to influence satiety or weight management, ${ }^{45,46}$ did not produce any effect on weight management.

\section{Ways of getting patients to adopt obesity-reducing behaviors}

In the last 50 years, behavioral therapy for the management of obesity has designed and evaluated several procedures and strategies to improve patients' long-term adherence to obesity-reducing behaviors. ${ }^{47}$ Originally, the treatment was based entirely on learning theory (ie, behaviorism), which assumes that behaviors leading to development and maintenance of obesity (overeating and underexercising) are mainly learned and can therefore be modified or relearned. The theory suggests that healthy changes in eating and exercising can be achieved by modifying the environmental cues (antecedents) and reinforcing these behaviors (consequences). ${ }^{48,49}$ Behavioral therapy was later combined with cognitive strategies (eg, problem solving and cognitive restructuring) and specific recommendations on diet and exercise, and this complex combination is referred to as "lifestyle modification". 50

Modern lifestyle modification programs have three main components: dietary recommendations; physical activity recommendations; and cognitive-behavioral therapy to address weight loss and weight maintenance obstacles (see Figure 1). ${ }^{51}$ These components interact with each other, each contributing to the final success of treatment.

\section{Diet}

Lifestyle modification programs recommend a low-calorie diet aimed at inducing a caloric deficit of 500-1,000 kcal/day and, thus, a weight loss of $0.5-1.0 \mathrm{~kg} /$ week. Very low-calorie diets (ie, $<800 \mathrm{kcal} /$ day) produce greater initial weight loss than low-calorie diets. ${ }^{52}$ However, long-term (ie, for more than one year) weight loss is not different from that of the low-calorie diets and may be associated with more medical complications. ${ }^{52}$

The standard lifestyle modification programs have been traditionally associated with low-fat, high-carbohydrate diets, as suggested by the clinical guidelines for treatment of obesity from the US National Institutes of Health. ${ }^{52}$ However, recent findings have challenged this recommendation because diets with a lower carbohydrate content and a higher protein-tocarbohydrate dietary ratio produced a greater weight loss at 6 months. ${ }^{53-55}$ However, the long-term (1-2 years) weight loss is minimal with both types of diet. ${ }^{56}$ The largest study published on this issue compared weight loss in 811 obese adults treated with four diets of different nutrient composition (ie, low-fat and average-protein versus low-fat and highprotein versus high-fat and average-protein versus high-fat and high-protein diet) but similar calorie contents. ${ }^{57}$ The four diets produced a similar weight loss of about $4 \mathrm{~kg}$ at

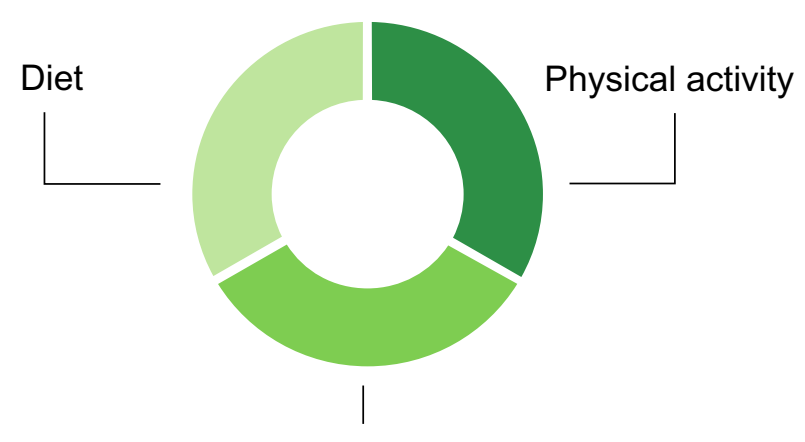

Cognitive behavioral therapy

Figure I Principal components of lifestyle modification programs. 
2 years ${ }^{57}$ suggesting that the diets' macronutrient composition is not important when the level of caloric restriction is held constant. A recent study, including a 21-day first phase of inpatient treatment and a 48-week outpatient treatment, confirmed that no differences in weight loss are expected between high-protein and high-carbohydrate diets. ${ }^{58}$ The authors suggested that the inpatient stage might have facilitated adherence to dietary prescription; the higher weight loss previously observed with high protein diets might thus be solely the effect of increased dietary adherence.

When selecting the macronutrient composition of diet, clinicians should mainly consider patient preferences, particularly those related to the ease of dietary adherence, and the desired changes in metabolic and cardiovascular risk factors. ${ }^{59}$ As a general indication, low-fat diets are associated with greater reductions in low-density lipoprotein cholesterol, whereas low-carbohydrate regimens are associated with greater improvements in triglycerides and high-density lipoprotein..$^{59}$

Adherence is improved by increasing dietary structure and limiting food choice. ${ }^{51}$ This conclusion is supported by a study showing that provision of both low-calorie food (free of charge or subsidized) and structured meal plans (ie, grocery lists, menus, and recipes) resulted in greater weight loss than a diet with no additional structure. ${ }^{60}$ Meal replacement is another effective strategy for increasing adherence, a statement supported by a meta-analysis of six randomized, controlled trials showing that liquid meal replacements produced a weight loss of $3 \mathrm{~kg}$ more than that of a conventional diet. ${ }^{61}$

\section{Physical activity}

Lifestyle modification programs recommend physical activity aimed at producing a caloric deficit of at least $400 \mathrm{kcal} /$ day. This goal can be achieved by educating patients to check their baseline number of steps with a pedometer and then gradually increase the number of steps (ie, adding 500 steps at 3-day intervals) to a target value of 10,000-12,000 steps per day. Jogging (20-40 minutes per day), biking or swimming (45-60 minutes per day) may be used by some patients as an alternative to walking.

Contrary to dietary adherence, exercise adherence tends to increase when less structure is imposed. ${ }^{51}$ For example, lifestyle activities (eg, using stairs rather than elevators, walking rather than taking a bus or driving, and reducing the use of labor-saving devices) led to a similar weight loss but longer weight maintenance than structured, programmed activity. ${ }^{62}$ Patients engage in physical activity more frequently when they do it on their own at home than when they are asked to attend supervised, group-based exercise sessions. ${ }^{63}$ Finally, multiple short sessions of exercise (10 minutes each) help patients to accumulate more daily minutes of exercise than long ones. ${ }^{64}$ However, at present, implementation of physical activity remains extremely challenging for the treatment of subjects with metabolic disorders, due to the pressure towards a sedentary lifestyle exerted in the Westernized world.$^{65}$

\section{Cognitive-behavioral therapy}

The cognitive-behavioral therapy component of lifestyle modification programs includes a set of procedures to address both weight loss and weight maintenance obstacles. They are presented in Tables 2 and 3, as described in the most recent manuals and articles on lifestyle modification programs..$^{51,66-78}$

Standard lifestyle modification programs are traditionally delivered in groups by different therapists as a series of

Table 2 Main cognitive procedures and strategies to address weight loss obstacles in obesity lifestyle modification programs

\section{Self-monitoring}

$\checkmark$ Patients are educated to write down the time, amount, type, and calorie content of foods and beverages they are going to consume in a monitoring record, and then to check in "real time", while eating, if they respect what they had planned. ${ }^{70}$

$\checkmark$ Physical activity can be recorded in the same way, in minutes of programmed activity and/or steps using a pedometer. ${ }^{51}$

$\checkmark$ Patients are also encouraged to check their weight regularly (eg, once a week) because frequent weighing is associated with better long-term weight maintenance. ${ }^{71}$

$\checkmark$ The more self-monitoring is used, the greater the weight loss. ${ }^{72}$ Goal setting

$\checkmark$ Patients are educated to plan specific and quantifiable weekly goals (for example, increasing I,000 steps a week), which should be realistic and moderately challenging. ${ }^{51}$

\section{Stimulus control}

$\checkmark$ Patients are encouraged to remove triggers for excessive eating and to increase positive cues for exercising.

$\checkmark$ They are also encouraged to increase positive cues for desirable behavior, and educated to create a reward system to reinforce adherence to eating control and exercising. ${ }^{51}$

\section{Alternative behaviors}

$\checkmark$ Patients are trained to identify internal eating cues (eg, craving or emotional stimuli) and to replace them with alternative behaviors. ${ }^{51}$

Proactive problem-solving

$\checkmark$ Patients are encouraged to screen for problems that might influence eating or trigger other dysfunctional behaviors in the following days and to apply the problem-solving procedure. ${ }^{73}$

\section{Cognitive restructuring}

$\checkmark$ The procedure is used to help patients challenge problematic thoughts that hinder adherence to lifestyle changes. Through this procedure, patients learn how strongly thoughts influence both mood and behavior and how much a more rational and functional way of thinking can help improve adherence to diet and physical activity. ${ }^{51}$ 
Table 3 Main cognitive procedures and strategies to address weight maintenance obstacles in obesity lifestyle modification programs

\section{Providing continuous care}

$\checkmark$ A continuous care model of treatment is probably necessary to provide patients with the support and motivation needed to continue to practice weight control behaviors. ${ }^{59} \mathrm{~A}$ meta-analysis of 13 studies found that patients who received long-term programs (4I sessions over 54 weeks) were able to maintain $10.3 \mathrm{~kg}$ of their initial $10.7 \mathrm{~kg}$ weight loss. $^{74}$

Building the long-term weight control mindset

$\checkmark$ Cognitive strategies to improve the adherence to practicing physical activity and adopting a long-term, low-calorie, low-fat diet are used to help patients in building a long-term weight control mindset. A study found that including cognitive procedures in lifestyle modification is associated with better weight loss maintenance, ${ }^{75}$ but this outcome was not confirmed by a randomized controlled trial. ${ }^{76}$

\section{Establishing weight maintenance range and long-term} self-monitoring of weight

$\checkmark$ Since frequent weight checking is associated with better weight maintenance, ${ }^{77,78}$ patients are recommended to check their weight at least once a week and to interpret any weight variation every 4 weeks. They are also encouraged to maintain their weight within a range of 2-3 $\mathrm{kg}$ (the weight maintenance binary) of their target to allow for natural weight fluctuation. ${ }^{70}$

\section{Constructing a weight maintenance plan}

$\checkmark$ Toward the end of treatment, patients should be helped to construct a written weight maintenance plan, which should include both procedures and strategies designed to maintain their weight and to address a possible weight gain over the established threshold. ${ }^{70}$

prepackaged lessons in preplanned order even if the patient has not overcome his/her problems or has failed to understand the procedures. On the contrary, the most recent lifestyle modification programs, such as the Diabetes Prevention Program $^{79}$ and that used in the Look AHEAD (Action for
Health in Diabetes) study, ${ }^{80}$ offer patients more individualized approaches, including a case manager in the team.

Whereas these procedures are well standardized and accepted in the clinical setting, they usually do not specifically address individual needs. A new strategy has been recently exploited at Villa Garda Hospital, aimed at tailoring an individual lifestyle modification program, identified as "constructing the personal formulation".

The personal formulation is a visual representation (a diagram) of the main cognitive-behavioral processes hindering weight loss in the patient. The formulation is created step by step in collaboration with the patient, and includes eating (ie, the sight of food, social eating situations) and/or noneating (ie, events and changes of mood) stimuli, positive emotional and/or physical consequences of food intake, and problematic thoughts influencing the patient's eating behavior (Figure 2). Later, the clinician should discuss its implications. The main argument is that the control of eating does not depend only on the patient's willpower but also on acquisition of specific strategies to address the cognitive behavior processes hindering adherence to the eating changes necessary to lose weight. The clinician should explain that the formulation is provisional and that it will be modified as needed during the course of treatment.

\section{Way of delivering lifestyle modification programs and results}

The treatment usually includes a weight loss phase, consisting of 16-24 weekly sessions in 6 months, followed by a weight maintenance phase ${ }^{81}$ While there is general agreement about the length of the weight loss phase because after 6 months

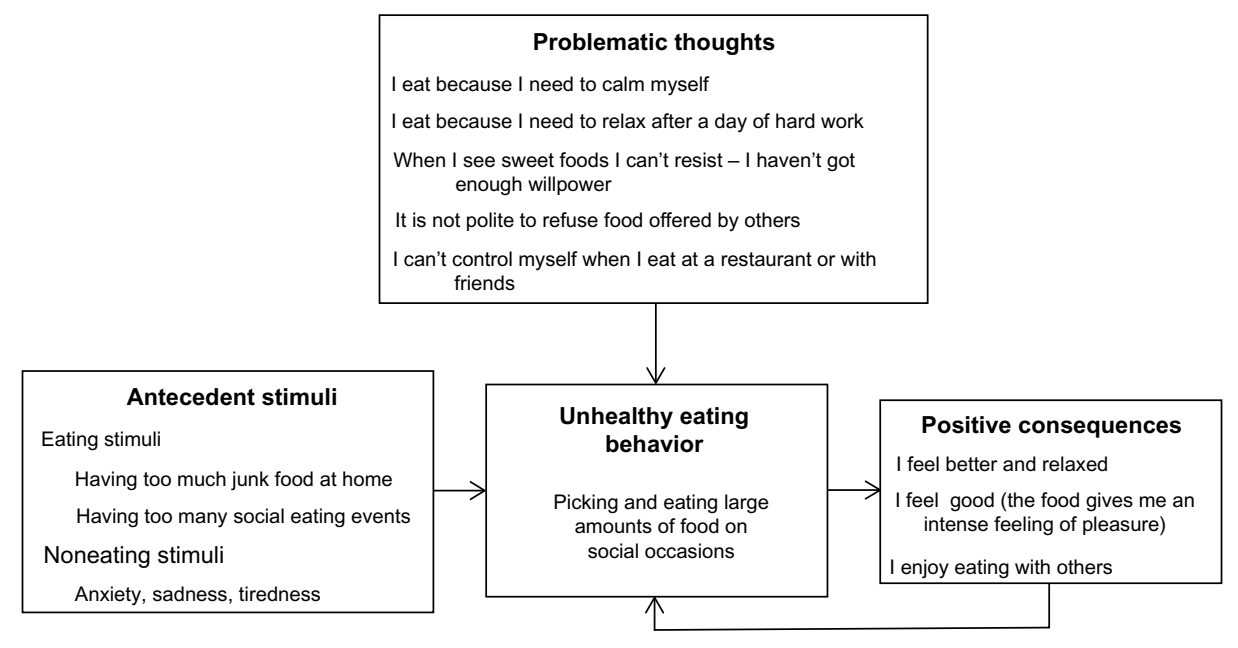

Figure 2 A patient's sample of the cognitive-behavioral formulation of his/her main obstacles to weight loss.

Notes: Based on this formulation, the treatment was designed to include cognitive-behavioral procedures and strategies to reduce food stimuli, to cope with noneating stimuli, to address stress and anxiety, and to challenge problematic thoughts. 
weight loss tends to reach a plateau, no definitive data are yet available about the optimal duration and intensity of the weight maintenance phase.

In research settings, lifestyle modification programs have been delivered in individual sessions (as in the Diabetes Prevention Program), ${ }^{79}$ in groups of about 10-20 participants ${ }^{47}$ or in a combination of group and individual sessions (as in the Look AHEAD study).$^{80}$ Randomized controlled trials evaluating the efficacy of lifestyle modification programs delivered in groups showed that completers (about $80 \%)^{82}$ achieved an average $8 \%-10 \%$ loss of initial weight in 30 weeks of treatment, ${ }^{82,83}$ an amount of weight loss that satisfies the criterion for success (ie, a 5\%-10\% reduction of initial weight) proposed by international obesity guidelines. ${ }^{5,84}$ A recent meta-analysis evaluating the effect of lifestyle modification programs (treatment range 13-52 sessions) found that at one year, 28\% of participants had a weight loss $\geq 10 \%$ of baseline weight, $26 \%$ of $5 \%-9.9 \%$, and $38 \%$ of $\leq 4.9 \% .{ }^{85}$ This amount of weight loss is associated with a significant reduction in the incidence of type 2 diabetes, ${ }^{86}$ as well as improvement in medical (eg, sleep apnea, diabetes, hypertension, and hyperlipidemia) and psychosocial (eg, mood, quality of life, and body image) outcomes. ${ }^{52,87-89}$ Unfortunately, participants regain about $30 \%-35 \%$ of the weight lost in the year following treatment, and after 5 years more than $50 \%$ of them return to their baseline weight. ${ }^{74}$

However, more recent lifestyle modification trials, including the most innovative and powerful weight loss lifestyle modification procedures and strategies (group and individual sessions under the guidance of a lifestyle modification counselor) show better long-term results. An example is the Look AHEAD study, a 13.5-year randomized trial that included 5,100 overweight participants with type 2 diabetes randomly assigned to an intensive lifestyle intervention or a diabetes support and education group. After 10 years, the participants assigned to intensive lifestyle intervention maintained a mean weight loss of $6 \%$ in comparison with $3 \%$ in the diabetes support and education group $(P<0.001)$. In addition, after 4 years, the intensive lifestyle intervention group maintained significantly greater improvement in hemoglobin $\mathrm{A}_{1 \mathrm{c}}$, fitness, high-density lipoprotein cholesterol, and systolic blood pressure than the diabetes support and education group,,$^{90}$ but did not show a reduction in cardiovascular events, ie, heart attack and stroke. For this reason, the US National Institutes of Health stopped the intervention arm in September 2012, and final data have been recently published..$^{91}$

A promising treatment reserved for individuals with severe obesity is combining lifestyle modification with an initial phase of residential rehabilitative treatment. A recent randomized, controlled study showed that a treatment including 3 weeks of residential lifestyle modification program followed by 12 individual sessions of 45 minutes each over 40 weeks with a trained dietitian produced a mean weight loss of about $15 \%$ with a significant improvement in cardiovascular risk factors and psychologic profiles. ${ }^{92}$ The percentage weight loss obtained in this study was higher than the mean $8 \%-10 \%$ obtained in conventional lifestyle modification programs. ${ }^{82,83}$

Lifestyle modification programs have also been delivered in the primary care setting, but the results in terms of weight loss and weight maintenance have been limited. ${ }^{93,94}$ Such poor results have been attributed to lack of physicians' time, repayment, and training. ${ }^{93}$ These factors make it difficult for physicians to add intensive weight management programs to an already busy daily practice.

On the contrary, promising results have been obtained delivering lifestyle modification programs in the community. For example, an adaptation of the Diabetes Prevention Program delivered in a workplace in a 16-session group treatment produced a weight loss of about $6.0 \%$ of initial weight after 6 months in comparison with a loss of $2.0 \%$ in a group that only received nutritional counseling. ${ }^{95}$ A significant difference was maintained after 12 months. Another study using an adaptation of the Diabetes Prevention Program delivered by trained staff of the local Cooperative Extension Service office to general population communities produced an average $10.0 \mathrm{~kg}$ weight loss after a 6-month lifestyle modification program. After this initial phase, participants were randomized into three arms (telephone counseling, face-to-face counseling, or newsletters twice a month) for another year. The telephone and face-to-face groups regained less weight (1.2 kg in both) in comparison with the newsletter group $(3.7 \mathrm{~kg})$, and was cost-effective also in a rural setting. ${ }^{96}$ The results of both studies demonstrate that lifestyle modification programs for weight loss and maintenance may be implemented in the community.

Recently, lifestyle modification programs have also been delivered via telephone and the Internet with promising results. The available data indicate that Internet programs induce a mean weight loss of about two thirds that achieved by traditional on-site delivery. ${ }^{97}$ In addition, studies comparing Internet-delivered programs with those delivered on-site or by phone found that person-to-person interventions are more effective in maintaining weight loss. However, the lower efficacy of the Internet intervention is somewhat counterbalanced by its easier accessibility, affordability, and convenience. ${ }^{59}$ 
Lifestyle modification programs have also been delivered and tested in a psychiatric rehabilitation setting with adults suffering from serious mental illness. ${ }^{98}$ Although weight loss is modest, there is now the possibility to use lifestyle modification procedures and strategies in individuals with severe psychiatry disorders, where obesity is an important problem due to physical inactivity ${ }^{99}$ and unhealthy diet, ${ }^{100}$ as well as psychotropic medications leading to weight gain. ${ }^{101}$

Finally, recent studies suggest that the outcome of bariatric surgery may be improved if the intervention is combined with a lifestyle modification. For example, in 144 Hispanic Americans randomized to a comprehensive nutrition and lifestyle educational intervention or to a control approach 6 months after gastric bypass surgery, ${ }^{102}$ the experimental intervention was followed by greater excess weight loss, and subjects were more involved in physical activity than the participants of the comparison group.

\section{Conclusion}

Despite intensive studies, our knowledge regarding predictors of weight loss and its maintenance remains largely incomplete; the evidence is that predictors are heterogeneous and predictive models are weak. We need to develop new research programs to reach the goal of matching treatments to patients' needs to improve successful weight loss and its maintenance. We also have to recognize that people might need different things at different points in their treatment cycle, and treatment tailored to patients' expectations at any specific time is mandatory. What might be of help in a chronic or acute state may be totally different from what is helpful in a maintenance stage. How to detect and address these needs is a continuous, challenging, research problem.

\section{Disclosure}

The authors declare no conflict of interests in relation to the material published in this study.

\section{References}

1. World Health Organization. WHO Global InfoBase 2013. Available at: http:// www.who.inf/ncd_surveillance/infobase/en. Accessed July 18, 2013.

2. Wang Y, Beydoun MA. The obesity epidemic in the United States gender, age, socioeconomic, racial/ethnic, and geographic characteristics: a systematic review and meta-regression analysis. Epidemiol Rev. 2007; 29:6-28.

3. Flegal KM, Carroll MD, Ogden CL, Curtin LR. Prevalence and trends in obesity among US adults, 1999-2008. JAMA. 2010;303(3):235-241.

4. World Health Organization. Obesity and overweight-fact sheet No 311. 2006. Available from: http://www.who.int/mediacentre/factsheets/fs311/ en/. Accessed May 5, 2013.

5. World Health Organization. Obesity: preventing and managing the global epidemic. Report of a WHO consultation. World Health Organ Tech Rep Ser. 2000;894:i-xii, 1-253.
6. Breaux CW. Obesity surgery in children. Obes Surg. 1995;5(3): 279-284.

7. Wang YC, McPherson K, Marsh T, Gortmaker SL, Brown M. Health and economic burden of the projected obesity trends in the USA and the UK. Lancet. 2011;378(9793):815-825.

8. Reilly JJ, Kelly J. Long-term impact of overweight and obesity in childhood and adolescence on morbidity and premature mortality in adulthood: systematic review. Int J Obes (Lond). 2011;35(7): 891-898.

9. LeBlanc E, O' Connor E, Whitlock EP, Patnode C, Kapka T. Screening for and Management of Obesity and Overweight in Adults. Evidence Synthesis No 89. AHRQ Publication No 11-05159-EF. Rockville, MD: Agency for Healthcare Research and Quality; 2011.

10. Mokdad AH, Ford ES, Bowman BA, et al. Diabetes trends in the US: 1990-1998. Diabetes Care. 2000;23(9):1278-1283.

11. Hill AJ, Magson LD, Blundell JE. Hunger and palatability: tracking ratings of subjective experience before, during and after the consumption of preferred and less preferred food. Appetite. 1984;5(4):361-371.

12. Wansink B. Mindless Eating: Why We Eat More than We Think. New York, NY: Bantam Books; 2001.

13. Stang J, Loth KA. Parenting style and child feeding practices: potential mitigating factors in the etiology of childhood obesity. JAm Diet Assoc. 2011;111(9):1301-1305.

14. Toft UN, Kristoffersen LH, Aadahl M, von Huth Smith L, Pisinger C, Jorgensen T. Diet and exercise intervention in a general populationmediators of participation and adherence: the Inter99 study. Eur J Publ Health. 2007;17(5):455-463.

15. Miller WR, Rollnick S. Motivational Interviewing. 2nd ed. New York, NY: The Guilford Press; 2002.

16. Festinger L. A Theory of Cognitive Dissonance. Evanston, IL: Row and Peterson; 1957.

17. Kanfer R. Task specific motivation: an integrative approach to issues of measurement, mechanisms, processes, and determinants. J Soc Clin Psychol. 1987;5:237-264.

18. Steele CM. The psychology of self-affirmation: sustaining the integrity of self. In: Berkowitz L, editor. Advances in Experimental and Social Psychology. New York, NY: Academic Press; 1988.

19. Bandura A. Self-efficacy in Changing Societies. Cambridge, UK: Cambridge University Press; 1995.

20. Rogers RW. A protection motivation theory of fear appeals and attitude change. J Psychol. 1975;91:93-114.

21. Prochaska JO, DiClemente CC. Transtheoretical therapy: toward a more integrative model of change. Psychotherapy. 1982;19(3):276-288.

22. Schwarzer R. Self-efficacy in the adoption and maintenance of health behaviors: theoretical approaches and a new model. In: Schwarzer R, editor. Self-efficacy: Thought Control of Action. Washington, DC: Hemesphere; 1992.

23. Ajzen I. The theory of planned behavior. Organ Behav Hum Decis Process. 1991;50:179-211.

24. Bandura A. Self-efficacy: The Exercise of Control. New York, NY: Freeman; 1997.

25. Oei TP, Burrow T. Alcohol expectancy and drinking refusal self-efficacy: a test of specificity theory. Addict Behav. 2000;25(4):499-507.

26. Baldwin AS, Rothman AJ, Hertel AW, et al. Specifying the determinants of the initiation and maintenance of behavior change: an examination of self-efficacy, satisfaction, and smoking cessation. Health Psychol. 2006;25(5):626-634.

27. Hendriksen ES, Pettifor A, Lee SJ, Coates TJ, Rees HV. Predictors of condom use among young adults in South Africa: the Reproductive Health and HIV Research Unit National Youth Survey. Am J Publ Health. 2007;97(7):1241-1248.

28. Kaewthummanukul T, Brown KC. Determinants of employee participation in physical activity: critical review of the literature. AAOHN J. 2006;54(6):249-261.

29. Sharma M, Sargent L, Stacy R. Predictors of leisure-time physical activity among African American women. Am J Health Behav. 2005;29(4): 352-359. 
30. Sallis JF, Haskell WL, Fortmann SP, Vranizan KM, Taylor CB, Solomon DS. Predictors of adoption and maintenance of physical activity in a community sample. Prev Med. 1986;15(4):331-341.

31. Sallis JF, Hovell MF, Hofstetter CR. Predictors of adoption and maintenance of vigorous physical activity in men and women. Prev Med. 1992;21(2):237-251.

32. Strachan SM, Woodgate J, Brawley LR, Tse A. The relationship of self-efficacy and self-identity to long-term maintenance of vigorous physical activity. J Appl Biobehav Res. 2005;10(2):98-112.

33. Wing RR, Hill JO. Successful weight loss maintenance. Anпu Rev Nutr. 2001;21:323-341.

34. Teixeira PJ, Going SB, Houtkooper LB, et al. Exercise motivation, eating, and body image variables as predictors of weight control. Med Sci Sports Exerc. 2006;38(1):179-188.

35. Biddle SJ, Fox KR. Motivation for physical activity and weight management. Int J Obes Relat Metab Disord. 1998;22 Suppl 2:S39-S47.

36. Ryan RM, Deci EL. Self-determination theory and the facilitation of intrinsic motivation, social development, and well-being. Am Psychol. 2000;55(1):68-78.

37. Russell HA, Rufus C, Fogarty CT, Fiscella K, Carroll J. 'You need a support. When you don't have that . . chocolate looks real good'. Barriers to and facilitators of behavioural changes among participants of a Healthy Living Program. Fam Pract. 2013;30(4):452-458.

38. Rossini R, Moscatiello S, Tarrini G, et al. Effects of cognitivebehavioral treatment for weight loss in family members. $J$ Am Diet Assoc. 2011;111(11):1712-1719.

39. Ohsiek S, Williams M. Psychological factors influencing weight loss maintenance: an integrative literature review. J Am Acad Nurse Pract 2011;23(11):592-601.

40. Dalle Grave R, Calugi S, Molinari E, et al. Weight loss expectations in obese patients and treatment attrition: an observational multicenter study. Obes Res. 2005;13(11):1961-1969.

41. Johnson F, Pratt M, Wardle J. Dietary restraint and self-regulation in eating behavior. Int J Obes (Lond). 2012;36(5):665-674.

42. Westenhoefer J, Stunkard AJ, Pudel V. Validation of the flexible and rigid control dimensions of dietary restraint. Int J Eat Disord. 1999; 26(1):53-64.

43. Teixeira PJ, Silva MN, Coutinho SR, et al. Mediators of weight loss and weight loss maintenance in middle-aged women. Obesity (Silver Spring). 2010;18(4):725-735.

44. Karhunen L, Lyly M, Lapvetelainen A, et al. Psychobehavioural factors are more strongly associated with successful weight management than predetermined satiety effect or other characteristics of diet. $J$ Obesity. 2012;2012:274068.

45. Paddon-Jones D, Westman E, Mattes RD, Wolfe RR, Astrup A, Westerterp-Plantenga M. Protein, weight management, and satiety. Am J Clin Nutr. 2008;87(5):1558S-1561S.

46. Wanders AJ, van den Borne JJ, de Graaf C, et al. Effects of dietary fibre on subjective appetite, energy intake and body weight: a systematic review of randomized controlled trials. Obes Rev. 2011;12(9): 724-739.

47. Wadden TA, Butryn ML, Byrne KJ. Efficacy of lifestyle modification for long-term weight control. Obes Res. 2004;12 Suppl:151S-162S.

48. Ferster CB, Nurberger I, Levitt EB. The control of eating. 1962. Obes Res. 1996;4(4):401-410.

49. Stuart RR. Behavioral control of overeating. Behav Ther. 1967;5: 357-365.

50. Wadden TA, McGuckin BG, Rothman RA, Sargent SL. Lifestyle modification in the management of obesity. J Gastrointest Surg. 2003;7(4):452-463.

51. Fabricatore AN. Behavior therapy and cognitive-behavioral therapy of obesity: is there a difference? J Am Diet Assoc. 2007;107(1):92-99.

52. National Institutes of Health. Clinical guidelines on the identification, evaluation, and treatment of overweight and obesity in adults - The Evidence Report. Obes Res. 1998;6 Suppl 2:51S-209S.

53. Foster GD, Wyatt HR, Hill JO, et al. A randomized trial of a lowcarbohydrate diet for obesity. $N$ Engl J Med. 2003;348(21):2082-2090.
54. Samaha FF, Iqbal N, Seshadri P, et al. A low-carbohydrate as compared with a low-fat diet in severe obesity. $N$ Engl J Med. 2003;348(21): 2074-2081.

55. Gardner CD, Kiazand A, Alhassan S, et al. Comparison of the Atkins, Zone, Ornish, and LEARN diets for change in weight and related risk factors among overweight premenopausal women: the A TO Z Weight Loss Study: a randomized trial. JAMA. 2007;297(9):969-977.

56. Nordmann AJ, Nordmann A, Briel M, et al. Effects of low-carbohydrate versus low-fat diets on weight loss and cardiovascular risk factors: a meta-analysis of randomized controlled trials. Arch Intern Med. 2006;166(3):285-293.

57. Sacks FM, Bray GA, Carey VJ, et al. Comparison of weight-loss diets with different compositions of fat, protein, and carbohydrates. $N$ Engl J Med. 2009;360(9):859-873.

58. Dalle Grave R, Calugi S, Gavasso I, El Ghoch M, Marchesini G. A randomized trial of energy-restricted high-protein versus highcarbohydrate, low-fat diet in morbid obesity. Obesity (Silver Spring). February 14, 2013. [Epub ahead of print].

59. Wadden TA, Webb VL, Moran CH, Bailer BA. Lifestyle modification for obesity: new developments in diet, physical activity, and behavior therapy. Circulation. 2012;125(9):1157-1170.

60. Wing RR, Jeffery RW, Burton LR, Thorson C, Nissinoff KS, Baxter JE. Food provision versus structured meal plans in the behavioral treatment of obesity. Int J Obes Relat Metab Disord. 1996;20(1):56-62.

61. Heymsfield SB, van Mierlo CA, van der Knaap HC, Heo M, Frier HI. Weight management using a meal replacement strategy: meta and pooling analysis from six studies. Int $J$ Obes Relat Metab Disord. 2003;27(5):537-549.

62. Andersen RE, Wadden TA, Bartlett SJ, Zemel B, Verde TJ, Franckowiak SC. Effects of lifestyle activity versus structured aerobic exercise in obese women: a randomized trial. JAMA. 1999;281(4): 335-340.

63. Perri MG, Martin AD, Leermakers EA, Sears SF, Notelovitz M. Effects of group-versus home-based exercise in the treatment of obesity. J Consult Clin Psychol. 1997;65(2):278-285.

64. Jakicic JM, Wing RR, Butler BA, Robertson RJ. Prescribing exercise in multiple short bouts versus one continuous bout: effects on adherence, cardiorespiratory fitness, and weight loss in overweight women. Int $J$ Obes Relat Metab Disord. 1995;19(12):893-901.

65. Montesi L, Moscatiello S, Malavolti M, Marzocchi R, Marchesini G. Physical activity for the prevention and treatment of metabolic disorders. Intern Emerg Med. May 9, 2013. [Epub ahead of print.]

66. Brownell KD. The LEARN Manual for Weight Management. Dallas, TX: American Health Publishing Co; 2000.

67. Cooper Z, Fairburn CG, Hawker DM. Cognitive-behavioral Treatment of Obesity: A Clinician's Guide. New York, NY: The Guilford Press; 2003.

68. Wadden TA, West DS, Delahanty L, et al. The Look AHEAD study: a description of the lifestyle intervention and the evidence supporting it. Obesity (Silver Spring). 2006;14(5):737-752.

69. Dalle Grave R, Calugi S, El Ghoch M. Lifestyle modification in the management of obesity: achievements and challenges. Eat Weight Disord. July 27, 2013. [Epub ahead of print.]

70. Cooper Z, Fairburn CG. A new cognitive behavioural approach to the treatment of obesity Behav Res Ther. 2001; 39(5):499-511.

71. O'Neil PM, Brown JD. Weighing the evidence: benefits of regular weight monitoring for weight control. J Nutr Educ Behav. 2005;37(6): 319-322.

72. Baker RC, Kirschenbaum DS. Self-monitoring may be necessary for successful weight control. Behav Ther. 1993;24:377-394.

73. Perri MG, Nezu AM, McKelvey WF, Shermer RL, Renjilian DA, Viegener BJ. Relapse prevention training and problem-solving therapy in the long-term management of obesity. $J$ Consult Clin Psychol. 2001;69(4):722-726.

74. Perri MG, Corsica JA. Improving maintenance of weight lost in behavioral treatment of obesity. In: Wadden T, Stunkard A, editors. Handbook of Obesity Treatment. New York, NY: Guilford Press; 2002. 
75. Stahre L, Tarnell B, Hakanson CE, Hallstrom T. A randomized controlled trial of two weight-reducing short-term group treatment programs for obesity with an 18-month follow-up. Int J Behav Med. 2007;14(1): 48-55.

76. Cooper Z, Doll HA, Hawker DM, et al. Testing a new cognitive behavioural treatment for obesity: a randomized controlled trial with three-year follow-up. Behav Res Ther. 2010;48(8):706-713.

77. Klem ML, Wing RR, McGuire MT, Seagle HM, Hill JO. A descriptive study of individuals successful at long-term maintenance of substantial weight loss. Am J Clin Nutr. 1997;66(2):239-246.

78. McGuire MT, Wing RR, Klem ML, Hill JO. Behavioral strategies of individuals who have maintained long-term weight losses. Obes Res. 1999;7(4):334-341.

79. Diabetes Prevention Program Study Group. The Diabetes Prevention Program (DPP): description of lifestyle intervention. Diabetes Care. 2002;25(12):2165-2171.

80. Ryan DH, Espeland MA, Foster GD, et al. Look AHEAD (Action for Health in Diabetes): design and methods for a clinical trial of weight loss for the prevention of cardiovascular disease in type 2 diabetes. Control Clin Trials. 2003;24(5):610-628.

81. Dalle Grave R, Calugi S, Centis E, Marzocchi R, El Ghoch M, Marchesini G. Lifestyle modification in the management of the metabolic syndrome: achievements and challenges. Diabetes Metab Syndr Obes. 2010;3:373-385.

82. Wadden TA, Butryn ML. Behavioral treatment of obesity. Endocrinol Metab Clin North Am. 2003;32(4):981-1003.

83. Expert Panel on the Identification, Evaluation, and Treatment of Overweight in Adults. Clinical guidelines on the identification, evaluation, and treatment of overweight and obesity in adults: executive summary. Am J Clin Nutr. 1998;68(4):899-917.

84. [No authors listed]. Executive summary of the clinical guidelines on the identification, evaluation, and treatment of overweight and obesity in adults. Arch Intern Med. 1998;158(17):1855-1867.

85. Christian JG, Tsai AG, Bessesen DH. Interpreting weight losses from lifestyle modification trials: using categorical data. Int J Obes (Lond). 2010;34(1):207-209.

86. Knowler WC, Barrett-Connor E, Fowler SE, et al. Reduction in the incidence of type 2 diabetes with lifestyle intervention or metformin. N Engl J Med. 2002;346(6):393-403.

87. Wing RR, Epstein LH, Marcus MD, Kupfer DJ. Mood changes in behavioral weight loss programs. J Psychosom Res. 1984;28(3):189-196.

88. Fontaine KR, Barofsky I, Bartlett SJ, Franckowiak SC, Andersen RE. Weight loss and health-related quality of life: results at 1-year follow-up. Eat Behav. 2004;5(1):85-88.
89. Dalle Grave R, Cuzzolaro M, Calugi S, et al. The effect of obesity management on body image in patients seeking treatment at medical centers. Obesity (Silver Spring). 2007;15(9):2320-2327.

90. Wing RR. Long-term effects of a lifestyle intervention on weight and cardiovascular risk factors in individuals with type 2 diabetes mellitus: four-year results of the Look AHEAD trial. Arch Intern Med. 2010; 170(17):1566-1575.

91. The Look AHEAD Research Group. Cardiovascular effects of intensive lifestyle intervention in type 2 diabetes. $N$ Engl J Med. 2013;369(2):145-154.

92. Donini LM, Cuzzolaro M, Spera G, et al. Obesity and eating disorders. Indications for the different levels of care. An Italian expert consensus document. Eat Weight Disord. 2010;15(Suppl 1-2):1-31. Italian.

93. Tsai AG, Wadden TA. Treatment of obesity in primary care practice in the United States: a systematic review. J Gen Intern Med. 2009;24(9): 1073-1079.

94. Ashley JM, St Jeor ST, Schrage JP, et al. Weight control in the physician's office. Arch Intern Med. 2001;161(13):1599-1604.

95. Perri MG, Limacher MC, Durning PE, et al. Extended-care programs for weight management in rural communities: the treatment of obesity in underserved rural settings (TOURS) randomized trial. Arch Intern Med. 2008;168(21):2347-2354.

96. Radcliff TA, Bobroff LB, Lutes LD, et al. Comparing costs of telephone versus face-to-face extended-care programs for the management of obesity in rural settings. J Acad Nutr Diet. 2012;112(9): 1363-1373.

97. Harvey-Berino J, West D, Krukowski R, et al. Internet delivered behavioral obesity treatment. Prev Med. 2010;51(2):123-128.

98. Daumit GL, Dickerson FB, Wang NY, et al. A behavioral weight-loss intervention in persons with serious mental illness. $N$ Engl J Med. 2013;368(17):1594-1602.

99. Lindamer LA, McKibbin C, Norman GJ, et al. Assessment of physical activity in middle-aged and older adults with schizophrenia. Schizophr Res. 2008;104(1-3):294-301.

100. Amani R. Is dietary pattern of schizophrenia patients different from healthy subjects? BMC Psychiatry. 2007;7:15.

101. Sachs GS, Guille C. Weight gain associated with use of psychotropic medications. J Clin Psychiatry. 1999;60 Suppl 21:16-19.

102. Nijamkin MP, Campa A, Sosa J, Baum M, Himburg S, Johnson P. Comprehensive nutrition and lifestyle education improves weight loss and physical activity in Hispanic Americans following gastric bypass surgery: a randomized controlled trial. JAcad Nutr Diet. 2012;112(3): 382-390.
Psychology Research and Behavior Management

\section{Publish your work in this journal}

Psychology Research and Behavior Management is an international, peerreviewed, open access journal focusing on the science of psychology and its application in behavior management to develop improved outcomes in the clinical, educational, sports and business arenas. Specific topics covered include: Neuroscience, memory \& decision making; Behavior

\section{Dovepress}

modification \& management; Clinical applications; Business \& sports performance management; Social and developmental studies; Animal studies. The manuscript management system is completely online and includes a quick and fair peer-review system. Visit http://www.dovepress. com/testimonials.php to read real quotes from published authors. 